\title{
EDITORIAL
}

\section{COMMEMORATIVE ISSUE}

\section{GOLDEN JUBILEE OF THE CLAY MINERALS GROUP}

The Clay Minerals Group of the Mineralogical Society of Great Britain and Ireland was 50 years old in January 1997. To mark the occasion, a meeting entitled 'Clay Mineralogy - Past, Present and Future' was held at The Macaulay Land Use Research Institute, Aberdeen from 9-11 April 1997 at which 45 papers covering all aspects of clay mineralogy were presented.

This issue of Clay Minerals is devoted to some papers presented at the Golden Jubilee Meeting plus a few others which were submitted independently through the normal channels for possible publication in this Commemorative issue.

The first article entitled 'The origin of the Clay Minerals Group' is the transcript of a recorded presentation made by D.M.C. MacEwan who was unable to attend the meeting but was a key figure in the formation of the Group in 1947 and its first Secretary. A full account of the history and development of the Group over the ensuing years was prepared for the meeting by J.A. Bain and copies of this are available through the Mineralogical Society.
The following three papers are reviews of clay mineralogy within the areas of soils, geology and industrial applications based on invited presentations by M.J. Wilson, J. Środoń and H.H. Murray, respectively.

The remaining 14 papers are mostly based on particular pieces of research but a few are of a more historical nature. Apart from the article by MacEwan, all manuscripts were subject to the normal review procedures and refereeing standards of the journal.

The Clay Minerals Group has always been international in outlook with speakers from overseas contributing to the inaugural meeting and papers published, initially in Clay Minerals Bulletin and subsequently in Clay Minerals, have clearly reflected this international dimension. This issue of Clay Minerals not only reflects the content and international flavour of the Golden Jubilee Meeting, but also the wide diversity of interests within the Group and the extraordinarily diverse nature of clay mineralogy.

D.C. BAIN 